Polymer Journal, Vol. 39, No. 4, pp. 330-341 (2007)

(C) 2007 The Society of Polymer Science, Japan

\title{
Characterization of Rodlike Poly(n-hexyl isocyanate) Macromonomers and Their Polymacromonomers by Light Scattering, SAXS, Intrinsic Viscosity, and Scanning Force Microscopy
}

\author{
Moriya KIKUChI, ${ }^{1}$ Taiki Minara, ${ }^{1}$ Yuji Jinbo, ${ }^{2}$ Yoshinobu IzUmi, ${ }^{2}$ \\ Katsutoshi NAGAI, ${ }^{1}$ and Seigou KAWAGUCHI ${ }^{1, \dagger}$ \\ ${ }^{1}$ Department of Polymer Science and Engineering, Faculty of Engineering, Yamagata University, \\ 4-3-16, Jonan, Yonezawa 992-8510, Japan \\ ${ }^{2}$ Graduate Program of Human Sensing and Functional Sensor Engineering, Graduate School \\ of Science and Engineering, Yamagata University, 4-3-16, Jonan, Yonezawa 992-8510, Japan
}

(Received November 27, 2006; Accepted December 29, 2006; Published February 26, 2007)

\begin{abstract}
SEC-MALS, small-angle X-ray scattering (SAXS), and viscosity measurements were made on tetrahydrofuran (THF) and $n$-hexane of a series of 4-vinylbenzyl and methacrylate ended poly $n$-hexyl isocyanate) (PHIC) macromonomers (VB-HIC- $n$ and MA-HIC- $n$, where $n$ is a degree of polymerization of HIC and in a range from 21 to 192), together with higher molecular weight PHIC chains than the macromonomers. The molecular weight dependence of z-average mean-square radius of gyration $\left\langle\mathrm{Rg}^{2}\right\rangle_{\mathrm{z}}$ and intrinsic viscosity $[\eta]$ of the macromonomers and PHIC chains in THF at $25^{\circ} \mathrm{C}$ were quantitatively described by the wormlike chain model with the stiffness parameter $\left(\lambda^{-1}\right)=63$ $\mathrm{nm}$, the molecular weight per unit contour length $\left(M_{\mathrm{L}}\right)=725 \mathrm{~nm}^{-1}$, and the hydrodynamic diameter $\left(d_{\mathrm{B}}\right)=1.6 \mathrm{~nm}$. The SAXS scattering profile of VB-HIC-57 in $n$-hexane at $25^{\circ} \mathrm{C}$ was also perfectly described in terms of the straight cylinder model. The results imply that the macromonomers may be regarded as a rigid rod molecule in THF and $n$-hexane. Cylindrical brushes consisting of polystyrene as a main chain and PHIC chains as a side chain were prepared by homopolymerizations of VB-HIC-46 and their dimensional properties were investigated in THF at $25^{\circ} \mathrm{C}$ by SAXS and SEC-MALS measurements. The molecular weight dependence of $\left\langle\mathrm{Rg}^{2}\right\rangle_{\mathrm{Z}}$ of the brushes was quantitatively explained by the wormlike cylinder model with the parameters of $\lambda^{-1}=48 \mathrm{~nm}, M_{\mathrm{L}}=2.40 \times 10^{4} \mathrm{~nm}^{-1}$, the cross-sectional radius of gyration of the cylinder $\left\langle\operatorname{Rc}^{2}\right\rangle_{0}{ }^{1 / 2}=4.66 \mathrm{~nm}$, and the end effect $(\delta=16.7 \mathrm{~nm})$ arising from side chains near the mainchain ends. It was concluded, therefore, that the main chain stiffness of the brush remarkably increases by the presence of densely located rodlike side chains. Direct observation of single brush of the poly(VB-HIC-46) deposited on a mica was made by scanning force microscopy (SFM) to reveal the cylindrical brushes consisting of rodlike side chains with ca. $15 \mathrm{~nm}$ in a thickness. [doi:10.1295/polymj.PJ2006173]

KEY WORDS Polymacromonomers / Rodlike Macromonomer / Dimensional Properties / SAXS / Chain Stiffness /
\end{abstract}

Macromonomers consisting of a macromolecular chain and a polymerizable end functional group have widely and successfully been used as building blocks for the synthesis of an enormous number of branched macromolecular architectures. ${ }^{1-4}$ Formally, the macromonomer homopolymerizes to afford a star- or comb-shaped polymer and copolymerizes with a conventional monomer to give a graft copolymer. Over the past two decades, a large number of macromonomers, differing in the type of the repeating monomer and the end-group have been prepared, thereby offering the possibility of construction of an enormous number of branched polymers in a variety of architectures, combinations, and compositions.

Since an initial report by Schmidt and Tsukahara et al. ${ }^{5}$ in 1994, poly(macromonomer)s, bottle brush macromolecules, or cylindrical polymer brushes have attracted considerable attention. The brushes are usu- ally prepared by homopolymerization of the macromonomers. A number of brush polymers consisting of flexible polymer side chains have been prepared, including polystyrene (PSt), ${ }^{5-13}$ poly(methyl methacrylate $),{ }^{14}$ poly(ethylene oxide $),{ }^{15-17}$ poly $(N$-isopropyl acrylamide),${ }^{18}$ poly $(n$-butyl acrylate) $){ }^{19}$ core-shell brushes consisting of block copolymers of styrene with 2-vinylpyridine, ${ }^{20}$ and $\varepsilon$-caprolactone with $n$-butyl acrylate. ${ }^{21}$ One interesting and important finding in conformational properties of the brushes with regular comb-branching structure is that the main chain remarkably stiffens in a solution, despite being composed of flexible chains and that the stiffness parameter $\left(\lambda^{-1}\right)$ in the wormlike cylinder model increases with side chain length and solvent power. ${ }^{5,8-13,16,17}$ Such stiffening effects may be reasonably considered to arise from repulsive interactions among side chains. Single cylindrical brush was also successfully ob-

${ }^{\dagger}$ To whom correspondence should be addressed (Tel/Fax: +81-238-26-3182, E-mail: skawagu@yz.yamagata-u.ac.jp). 


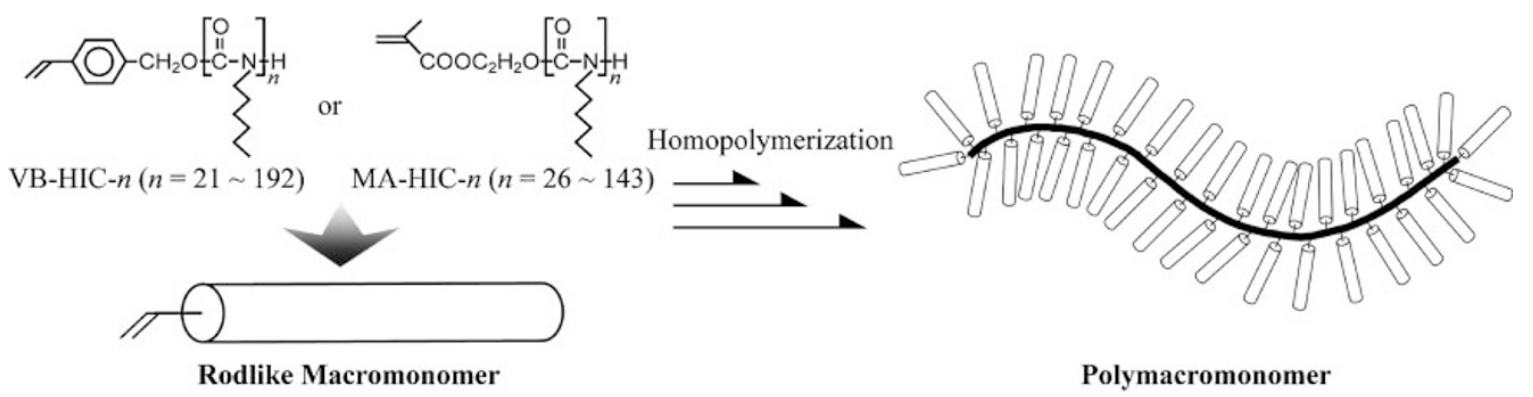

Scheme 1. Reaction scheme of cylindrical brush using rodlike macromonomer.

served by the scanning force microscopy (SFM) to clearly demonstrate the cylindrical conformation in a two-dimensional solid state. ${ }^{17,21-23}$

However, cylindrical brushes are limited to those consisting of flexible main and side chains in solution. Little is known about the experimental work of the brushes consisting of semi-flexible, or rodlike polymer chains as s side chain, except for Monte Carlo simulation $^{24}$ and theoretical study. ${ }^{25}$ According to the simulation results, the chain stiffness parameter $\left(\lambda^{-1}\right)$ of the main chain becomes much larger with the rigid side chains than with flexible side chains. ${ }^{24}$ The theoretical study based on the mean-field approach, the $\lambda^{-1}$ of the main chain is proportional to $\mathrm{L}^{2} / \ln (\mathrm{L})$, where $\mathrm{L}$ is the contour length of the side chain. ${ }^{25}$ It may be quite interesting and essential, therefore, to clarify how side chain flexibilities affect on the main chain stiffness. Recently, Schmidt et al. ${ }^{26}$ have prepared cylindrical brushes consisting of rodlike poly(L-lysine) and poly(L-glutamate) side chains by grafting through and grafting from techniques. Unfortunately, the grafting density was incomplete (about $40-50 \%$ ) by the grafting from method and weight average degree of polymerization $\left(\mathrm{N}_{\mathrm{w}}\right)$ of the main chain was very low $\left(\mathrm{N}_{\mathrm{w}}\right.$ is $c a$. 4) by the grafting through method.

In our previous papers, we have reported the syntheses of 4-vinylbenzyl and methacrylate ended rodlike $\operatorname{poly}(n$-hexyl isocyanate) (PHIC) macromonomers (VB-HIC- $n$ and MA-HIC- $n$ ) and their radical copolymerization behavior. ${ }^{27,28}$ PHIC is well-known to be a typical semi-flexible chain and one of the best characterized polyisocyanates with a dynamic $8_{3}$ helical conformation with $\lambda^{-1}=86 \mathrm{~nm}$ and the molecular weight per unit contour length, $M_{\mathrm{L}}=730 \mathrm{~nm}^{-1}$ in $n$-hexane at $25^{\circ} \mathrm{C} .{ }^{29,30}$

In this article, we report many details of the molecular characterizations of PHIC macromonomers and their polymacromonomers by small-angle X-ray scattering (SAXS), SEC-MALS, and viscometry in THF and $n$-hexane at $25^{\circ} \mathrm{C}$, as shown in the following scheme. Especially, we focus on the main chain stiffness of the cylindrical brush by the presence of rodlike side chains. Single brush observed by the SFM is also presented.

\section{EXPERIMENTAL}

\section{Materials}

PHIC macromonomers (VB-HIC- $n$ and MA-HIC- $n$ ) were prepared by the initiator method of a living coordination polymerization of HIC using a corresponding titanium alkoxide complex (IV) as an initiator, according to Novak method. ${ }^{31}$ The details for preparation were described in the previous papers. ${ }^{27,28}$ To make a calibration curve in an SEC with a series of PHIC's as a standard, five PHIC samples with a broad molecular weight distribution were prepared by an anionic polymerization of HIC using a sodium naphthalenide as an initiator in THF at $-78^{\circ} \mathrm{C}$. They were fractionated by repeating fractional precipitation with benzene as a solvent and methanol as a precipitant. The molecular weight and retention time of the fractionated PHIC chains were measured by SEC-MALS in THF.

Polymacromonomer, poly(VB-HIC-46) samples were prepared by radical homopolymerizations of VB-HIC-46 using dimethyl 2, 2'-azobis(2-methyl propionate) (V-601) as an initiator in $n$-hexane at $60^{\circ} \mathrm{C}$ for $24 \mathrm{~h}$. The conversions were determined by RI signal ratio of homopolymer to macromonomer and $c a$. $83 \%$. The reaction mixtures were dissolved into benzene and freeze-dried, followed by washing $n$-hexane to remove unreacted (unpolymerizaed) macromonomer. $98 \%$ of unreacted macromonomer could be removed by this procedure. To completely remove the unreacted macromonomer, the products were further fractionated by repeating fractional precipitations with toluene as a solvent and acetonitrile as a precipitant.

\section{Measurements}

Molecular weight and molecular weight distribution of macromonomers were determined by SEC (eluent; THF, flow rate; $1.0 \mathrm{~mL} / \mathrm{min}, 40^{\circ} \mathrm{C}$, columns; Shodex KF802 + KF806L + KF806L, RI; Shodex RI-101, UV; Tosoh UV-8020), calibrated with a series of 
PHIC's as a standard.

Weight average molecular weight $\left(M_{\mathrm{w}}\right), \mathrm{z}$-average mean-square radius of gyration $\left\langle\mathrm{Rg}^{2}\right\rangle_{\mathrm{Z}}$, and intrinsic viscosity of PHIC chain were determined by SECMALS-VIS (eluent; THF, flow rate; $1.0 \mathrm{~mL} / \mathrm{min}, 40$ ${ }^{\circ} \mathrm{C}$, columns; Shodex KF802 + KF806L + KF806L, RI; Shodex RI-101, UV; Tosoh UV-8020), equipped with a multi-angle light scattering detector (MALS; Wyatt Technology DAWN-DSP, wavelength; $\lambda=$ $632.8 \mathrm{~nm}$ ) and a viscometer (VIS; Viscotek Technology T-60A Dual Detector) at room temperature of $25 \pm 1{ }^{\circ} \mathrm{C}$. The Rayleigh ratio $\mathrm{R}(90)$ at a scattered angle of $90^{\circ}$ was based on that of pure toluene at wavelength of $632.8 \mathrm{~nm}$ at $25^{\circ} \mathrm{C}$. The corrections for sensitivity of 17 detectors at angles of other than $90^{\circ}$ and dead volume for each detector were performed using the scattering intensities of $0.30 \mathrm{wt} \%$ THF solution of polystyrene standard with $M_{\mathrm{w}}=1.88 \times 10^{4}$. RI detector was calibrated with a series of $\mathrm{NaCl}$ solutions. Viscometer was calibrated with the value $([\eta]=$ $0.136_{6} \mathrm{dL} / \mathrm{g}$ ) for THF solution of the polystyrene standard with $M_{\mathrm{w}}=1.88 \times 10^{4} . M_{\mathrm{w}}$ and $\left\langle\mathrm{Rg}^{2}\right\rangle_{\mathrm{z}}$ of polymacromonomer were measured in THF by SECMALS at room temperature of $25 \pm 1{ }^{\circ} \mathrm{C}$.

Specific refractive index increments $(\mathrm{d} n / \mathrm{d} c)$ for macromonomers and poly(VB-HIC-46) in THF at $25^{\circ} \mathrm{C}$ were measured using a differential refractometer (Otsuka Electronics DRM-1021, wavelength; $\lambda=$ $632.8 \mathrm{~nm}$ ).

Sample solutions were prepared by the gravimetric method. Weight fraction, $W_{\mathrm{p}}$ is then converted to $C_{\mathrm{p}}(\mathrm{g} / \mathrm{mL})$ by

$$
C_{\mathrm{p}}(\mathrm{g} / \mathrm{mL})=\frac{W_{\mathrm{p}}}{\rho_{\mathrm{o}}^{-1}\left(1-W_{\mathrm{p}}\right)+v W_{\mathrm{p}}}
$$

where $\rho_{\mathrm{o}}$ is the density of pure solvent $(0.65495 \mathrm{~g} / \mathrm{mL}$ for $n$-hexane and $0.8830 \mathrm{~g} / \mathrm{mL}$ for THF at $25^{\circ} \mathrm{C}$ ) and $v$ is the partial specific volume of PHIC $(0.950 \mathrm{~mL} / \mathrm{g}$ for $n$-hexane ${ }^{29}$ and $1.00 \mathrm{~mL} / \mathrm{g}$ for $\mathrm{THF}^{32}$ at $25^{\circ} \mathrm{C}$ ).

Small-angle X-ray scattering (SAXS) measurements were carried out at $25^{\circ} \mathrm{C}$, using BL-10C with a synchrotron orbital radiation as an X-ray source set up in the Photon Factory of the High Energy Accelerator Organization at Tsukuba, Ibaraki, Japan. The wavelength of the X-ray was $1.488 \AA$. The scattered intensity was recorded by a position-sensitive proportional counter (PSPC) with 512 channels over a scattering vector range from 0.02 to $0.30 \AA^{-1}$. The scattered vector was calibrated using a sixth peak of dry collagen. The details of the instrumentation and the procedure are described elsewhere. ${ }^{33}$

The viscosity measurements of macromonomers were carried out using a conventional dilution Ubbelohde tybe capillary viscometer in THF and $n$-hexane at $25^{\circ} \mathrm{C}$. The Huggins plot, ${ }^{34}$ the Fuoss-Mead plot,${ }^{35}$ and the Billmeyer plot $^{36}$ were combined to determine $[\eta]$.

Scanning force microscopy (SFM) was recorded with a Nanoscope III (Veeko Instrument Inc., USA) operated in the tapping mode for the polymer on mica, at room temperature. The samples for SFM measurements were prepared by drop casting from THF solution $\left(W_{\mathrm{p}}=5.0 \times 10^{-6} \mathrm{w} / \mathrm{w}\right)$ at room temperature.

\section{RESULTS AND DISCUSSION}

First, we report the characterization results for PHIC macromonomers in THF and $n$-hexane and demonstrate that the macromonomers are considered as a stiff cylinder in solution. Second, dimensional characterizations of the polymacromonomers consisting of the cylinders as a side chain in THF are described.

\section{Characterization of Macromonomers and PHIC in THF and n-Hexane}

The characterization results of VB-HIC- $n$ and MAHIC- $n$ prepared by a coordination polymerization with a titanium alkoxide complex (IV) as an initiator are summarized in Table I. Figure 1 shows the dependence of $(\mathrm{d} n / \mathrm{d} c)$ value on the degree of polymerization $(n)$ of macromonomer in THF at $25^{\circ} \mathrm{C}$. The solid lines show theoretical curve calculated by

$\left(\frac{\mathrm{d} n}{\mathrm{~d} c}\right)_{\text {Macromonomer }}=\left(\frac{\mathrm{d} n}{\mathrm{~d} c}\right)_{\text {PHIC }}\left(1-W_{\mathrm{i}}\right)+\left(\frac{\mathrm{d} n}{\mathrm{~d} c}\right)_{\mathrm{i}} W_{\mathrm{i}}$

where $W_{\mathrm{i}}$ (i is an ended styrene or 2-hydroxyethyl methacrylate (HEMA) group) is the weight fraction of the terminal double bond group. The $(\mathrm{d} n / \mathrm{d} c)$ values for styrene and HEMA in THF at $25^{\circ} \mathrm{C}$ were also determined 0.161 and $0.047_{0} \mathrm{~mL} / \mathrm{g}$, respectively. It is seen in this figure that the $(\mathrm{d} n / \mathrm{d} c)$ value of the macromonomers steeply increases or decreases with increasing $n$ in a low $n$ region and becomes almost constant at $n$ higher than 50. Theoretical lines calculated with $(\mathrm{d} n / \mathrm{d} c)_{\text {PHIC }}=0.088_{0} \mathrm{~mL} / \mathrm{g}$ for the PHIC chain well describe $n$-dependence of $(\mathrm{d} n / \mathrm{d} c)$ in THF at $25^{\circ} \mathrm{C}$. Therefore, this allows one to use the value of $0.088_{0}$ $\mathrm{mL} / \mathrm{g}$ for determination of the $M_{\mathrm{w}}$ of PHIC chains in THF at $25^{\circ} \mathrm{C}$, at least for $n>50$.

Figure 2 shows a typical SEC curve of VB-HIC-27, together with the calibration curves for polystyrene (PSt) and PHIC standards. One sees that the calibration curve with PHIC remarkably differs from that with PSt. The differences are observed both in the value of $M_{\mathrm{w}}$ at the same retention time and the slope of $\log \left(M_{\mathrm{w}}\right)$ with the retention time. This result clearly demonstrates that the $M_{\mathrm{w}}$ and the polydispersity index $\left(M_{\mathrm{w}} / M_{\mathrm{n}}\right)$ of PHIC chain determined with a conven- 
Main Chain Stiffness of Cylindrical Brushes Consisting of Rodlike Side Chains

Table I. Characterization results from SEC-MALS, SAXS and viscometry on PHIC macromonomer (VB-HIC- $n$ and MA-HIC- $n$ ) in $n$-hexane and THF at $25^{\circ} \mathrm{C}$

\begin{tabular}{|c|c|c|c|c|c|c|c|}
\hline \multirow{2}{*}{ Sample } & \multirow{2}{*}{$\begin{array}{l}\mathrm{d} n / \mathrm{d} c^{\mathrm{a})} \\
(\mathrm{mL} / \mathrm{g})\end{array}$} & \multirow{2}{*}{$\frac{\left.M_{\mathrm{w}} \times 10^{-4 \mathrm{~b}}\right)}{(\mathrm{SEC})}$} & \multirow{2}{*}{$\frac{\left.M_{\mathrm{w}} / M_{\mathrm{n}}^{\mathrm{b}}\right)}{(\mathrm{SEC})}$} & \multicolumn{2}{|c|}{$\left\langle\mathrm{Rg}^{2}\right\rangle_{\mathrm{z}, \mathrm{o}}{ }^{1 / 2}(\mathrm{~nm})$} & \multicolumn{2}{|c|}{$[\eta]\left(\mathrm{cm}^{3} / \mathrm{g}\right)$} \\
\hline & & & & $n$-hexane c) $^{\text {( }}$ & $\mathrm{THF}^{\mathrm{c})}$ & $n$-hexane & THF \\
\hline VB-HIC-21 & - & 0.281 & $1.1_{9}$ & 1.20 & - & - & - \\
\hline VB-HIC-27 & $0.091_{6}$ & 0.388 & $1.1_{1}$ & - & - & 7.02 & 5.79 \\
\hline VB-HIC-34 & - & 0.433 & $1.1_{8}$ & 1.76 & - & - & - \\
\hline VB-HIC-46 & $0.088_{8}$ & 0.605 & $1.1_{5}$ & - & 2.51 & 10.9 & 10.2 \\
\hline VB-HIC-57 & $0.089_{0}$ & 0.795 & $1.2_{0}$ & 3.28 & - & 一 & - \\
\hline VB-HIC-75 & $0.088_{0}$ & 1.03 & $1.1_{6}$ & - & 3.98 & 18.8 & 17.3 \\
\hline VB-HIC-118 & $0.087_{4}$ & 1.51 & $1.2_{8}$ & - & - & 31.6 & - \\
\hline VB-HIC-119 & $0.088_{2}$ & 1.52 & $1.4_{0}$ & 6.50 & - & - & - \\
\hline VB-HIC-192 & $0.089_{2}$ & 2.45 & $1.3_{3}$ & - & - & 60.0 & - \\
\hline MA-HIC-26 & $0.085_{0}$ & 0.408 & $1.0_{6}$ & 1.69 & - & 一 & - \\
\hline MA-HIC-43 & $0.086_{9}$ & 0.755 & $1.0_{9}$ & 2.96 & - & - & - \\
\hline MA-HIC-91 & - & 1.46 & $1.1_{2}$ & 5.78 & - & - & - \\
\hline MA-HIC-95 & $0.087_{1}$ & 1.23 & $1.4_{0}$ & - & - & - & - \\
\hline MA-HIC-141 & - & 1.87 & $1.1_{6}$ & 7.06 & - & - & - \\
\hline MA-HIC-143 & $0.087_{8}$ & 2.02 & $1.0_{9}$ & - & - & - & - \\
\hline
\end{tabular}

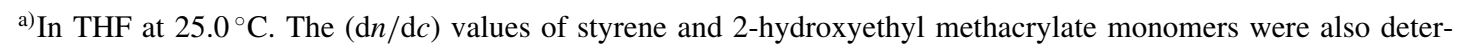
mined to be $0.161 \mathrm{~mL} / \mathrm{g}$ and $0.047_{0} \mathrm{~mL} / \mathrm{g}$, respectively. ${ }^{\text {b) }}$ Determined by SEC calibrated with a series of PHIC's as a standard. ${ }^{\mathrm{c})}$ Determined by SAXS at $25.0^{\circ} \mathrm{C}$.

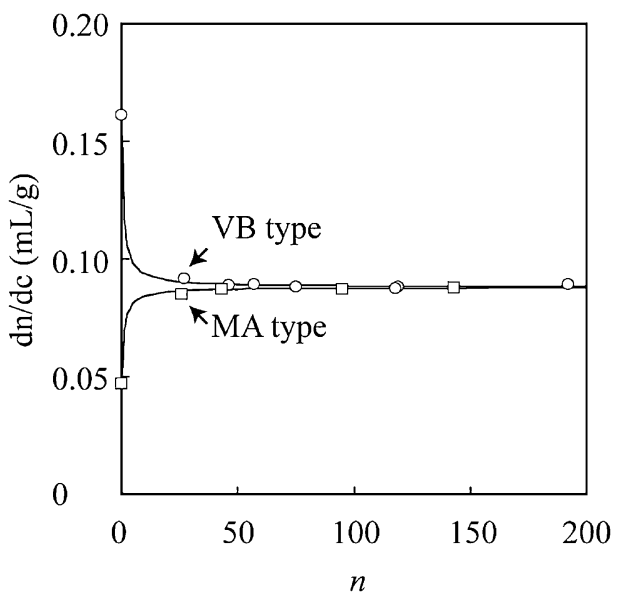

Figure 1. Plots of $(\mathrm{d} n / \mathrm{d} c)$ value versus the degree of polymerization $(n)$ of HIC for VB-HIC- $n$ and MA-HIC- $n$ in THF at $25^{\circ} \mathrm{C}$.

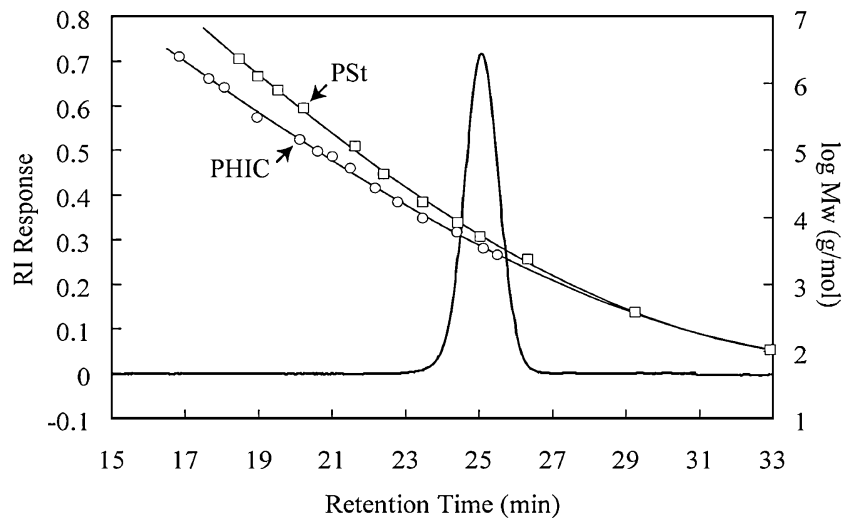

Figure 2. SEC curve of VB-HIC-27 in THF together with the calibration curves made by using polystyrene and PHIC standards.

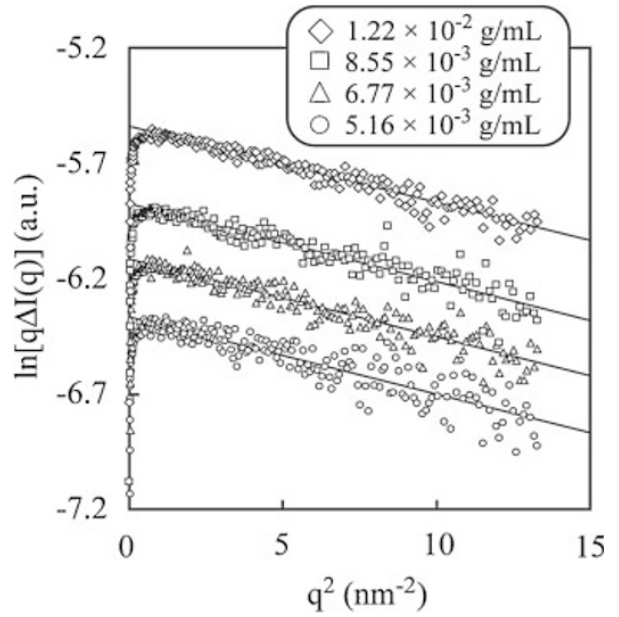

Figure 3. Cross-section plots of $\ln [q \Delta \mathrm{I}(q)]$ as a function $q^{2}$ for VB-HIC-57 in $n$-hexane at $25^{\circ} \mathrm{C}$.

tional PSt calibration curve are significantly overestimated. The values of $M_{\mathrm{w}}$ and $M_{\mathrm{w}} / M_{\mathrm{n}}$ determined by using a PHIC calibration curve are presented in Table I.

Cross-section Guinier plots of $\ln [q \Delta \mathrm{I}(q)]$ versus $q^{2}$ obtained for SAXS measurements of VB-HIC-57 in $n$ hexane at $25^{\circ} \mathrm{C}$ at various $C_{\mathrm{p}}$ 's are shown in Figure 3. The cross-sectional radius of gyration $\left\langle\mathrm{Rc}^{2}\right\rangle^{1 / 2}$ of the VB-HIC-57 molecule may be determined via the following equation: ${ }^{37}$

$$
\ln [\Delta \mathrm{I}(q) q]=\ln \frac{k^{2} N \pi}{L}-\frac{1}{2}\left\langle\operatorname{Rc}^{2}\right\rangle q^{2}
$$

Here $\Delta \mathrm{I}(q)$ is the experimental excess scattering in- 


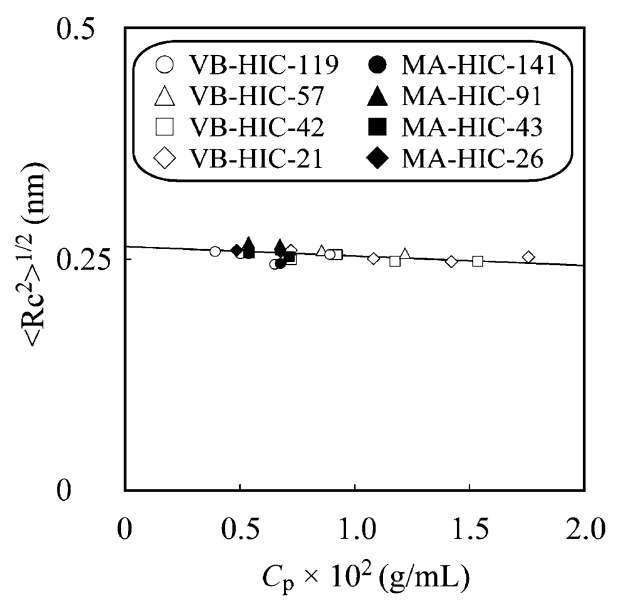

Figure 4. $C_{\mathrm{p}}$ dependence of the cross-sectional radius of gyration $\left\langle\mathrm{Rc}^{2}\right\rangle^{1 / 2}$ for VB-HIC- $n$ and MA-HIC- $n$ in $n$-hexane at $25^{\circ} \mathrm{C}$.

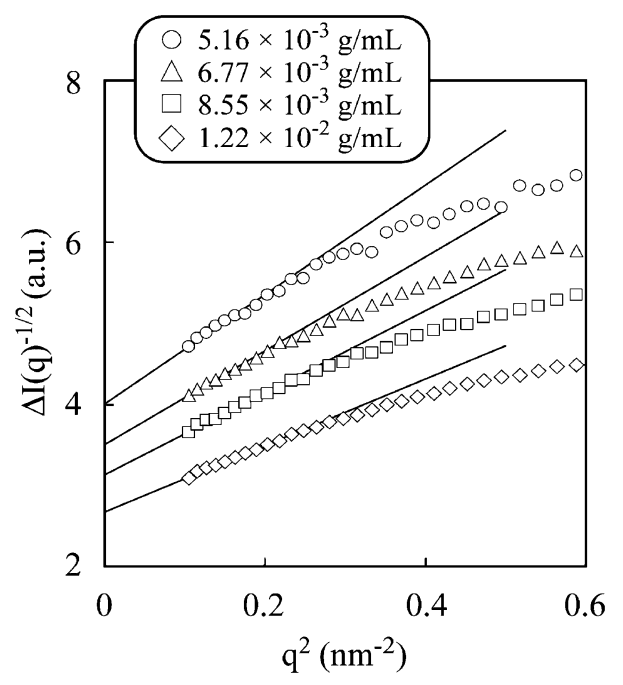

Figure 5. Berry plots of $\Delta \mathrm{I}(q)^{-1 / 2}$ as a function of $q^{2}$ for VBHIC-57 in $n$-hexane at $25^{\circ} \mathrm{C}$.

tensity, $L$ the contour length of the cylinder, $k$ the electron density contrast factor, $\mathrm{N}$ the number of cylinder, and $q$ is the scattering vector as defined with the scattering angle of $\theta$ and the wavelength of $\lambda$ by

$$
q=\frac{4 \pi \sin \theta}{\lambda}
$$

Figure 4 shows $C_{\mathrm{p}}$-dependence of $\left\langle\mathrm{Rc}^{2}\right\rangle^{1 / 2}$ for various PHIC macromonomers in $n$-hexane at $25^{\circ} \mathrm{C}$. By extrapolating to $C_{\mathrm{p}}=0$, one obtains the value of $0.263 \mathrm{~nm}$ for $\left\langle\mathrm{Rc}^{2}\right\rangle_{\mathrm{o}}{ }^{1 / 2}$ of a PHIC macromonomer at an infinite dilution. This value may correspond to $0.744 \mathrm{~nm}$ in a diameter (d) for a PHIC chain by the equation:

$$
\left\langle\operatorname{Rc}^{2}\right\rangle_{\mathrm{o}}=\frac{d^{2}}{8}
$$

Figure 5 shows the Berry's square-root plots of $\Delta \mathrm{I}(q)^{-1 / 2}$ as a function of $q^{2}$ for VB-HIC-57 in $n$-hex-

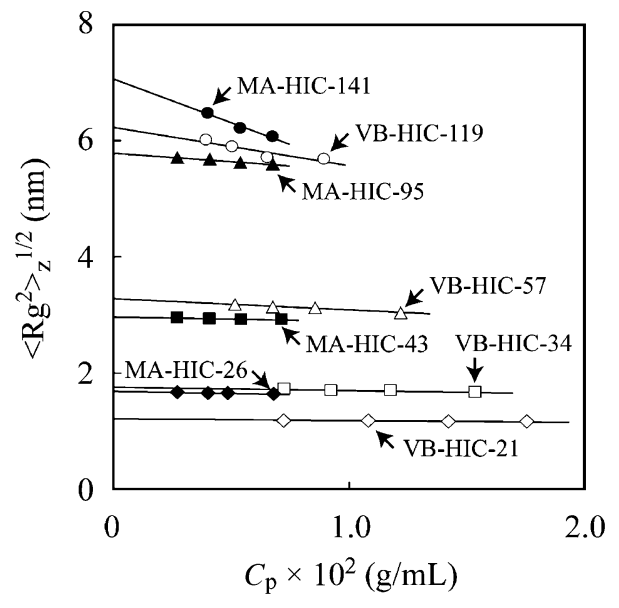

Figure 6. Plots of $\left\langle\operatorname{Rg}^{2}\right\rangle_{\mathrm{z}}{ }^{1 / 2}$ as a function of $C_{\mathrm{p}}$ for VB-HIC- $n$ and MA-HIC- $n$ in $n$-hexane at $25^{\circ} \mathrm{C}$.

ane at $25^{\circ} \mathrm{C}$. From the initial slope and intercept in these plots, one determines $\left\langle\operatorname{Rg}^{2}\right\rangle_{z}{ }^{1 / 2}$ by the following equation:

$$
\Delta \mathrm{I}(q)^{-1 / 2}=\Delta \mathrm{I}(0)^{-1 / 2}+\frac{1}{6} \Delta \mathrm{I}(0)^{-1 / 2}\left\langle\operatorname{Rg}^{2}\right\rangle_{\mathrm{z}} q^{2}
$$

Figure 6 shows the $C_{\mathrm{p}}$-dependence of $\left\langle\mathrm{Rg}^{2}\right\rangle_{\mathrm{z}}{ }^{1 / 2}$ for the corresponding PHIC macromonomers in $n$-hexane. In this figure, a slight decrease of the $\left\langle\operatorname{Rg}^{2}\right\rangle_{z}{ }^{1 / 2}$ value is noticed with increasing $C_{\mathrm{p}}$ and this is due to the positive second virial coefficient in $n$-hexane at $25^{\circ} \mathrm{C}$. To eliminate concentration effects, the $\left\langle\operatorname{Rg}^{2}\right\rangle_{z, 0}{ }^{1 / 2}$ value at an infinite dilution was determined via an extrapolation to the zero concentration. The $\left\langle\operatorname{Rg}^{2}\right\rangle_{z, 0}{ }^{1 / 2}$ values in THF at $25^{\circ} \mathrm{C}$ were also determined by the same method. These values are summarized in Table I.

In Figure 7 the plots of $\mathrm{P}(q)^{-1 / 2}$ versus $q^{2}$ for PHIC chains with higher $M_{\mathrm{w}}$ than macromonomers fractionated by SEC-MALS in THF are illustrated, where $\mathrm{P}(q)$ denotes the single particle scattering function. From the initial slope (denoted by solid line) in these plots, one determines $\left\langle\mathrm{Rg}^{2}\right\rangle_{\mathrm{z}}{ }^{1 / 2}$ of PHIC chain in THF at $25 \pm 1{ }^{\circ} \mathrm{C}$ via the following equation:

$$
\mathrm{P}(q)^{-1 / 2}=1+\frac{1}{6}\left\langle\operatorname{Rg}^{2}\right\rangle_{\mathrm{z}} q^{2}, \text { and } q=\frac{4 \pi n_{\mathrm{o}} \sin (\theta / 2)}{\lambda}
$$

where $n_{\mathrm{o}}$ is the refractive index of THF. The characteristics of PHIC chain in THF are listed in Table II.

Double-logarithmic plots of $\left\langle\operatorname{Rg}^{2}\right\rangle_{z, 0}{ }^{1 / 2}$ (SAXS) and $\left\langle\operatorname{Rg}^{2}\right\rangle_{\mathrm{z}}{ }^{1 / 2}$ (SEC-MALS) versus $M_{\mathrm{w}}$ for PHIC chains and macromonomers in THF and $n$-hexane at $25 \pm 1$ ${ }^{\circ} \mathrm{C}$ are depicted in Figure 8, together with the data reported by Norisuye et al..$^{29,30}$ in $n$-hexane at $25^{\circ} \mathrm{C}$.

The mean-square radius of gyration $\left(\left\langle\operatorname{Rg}^{2}\right\rangle\right)$ of a cylindrical wormlike chain ${ }^{38}$ is expressed by

$$
\left\langle\operatorname{Rg}^{2}\right\rangle=\left\langle\operatorname{Rg}^{2}\right\rangle_{\mathrm{KP}}+\left\langle\mathrm{Rc}^{2}\right\rangle
$$




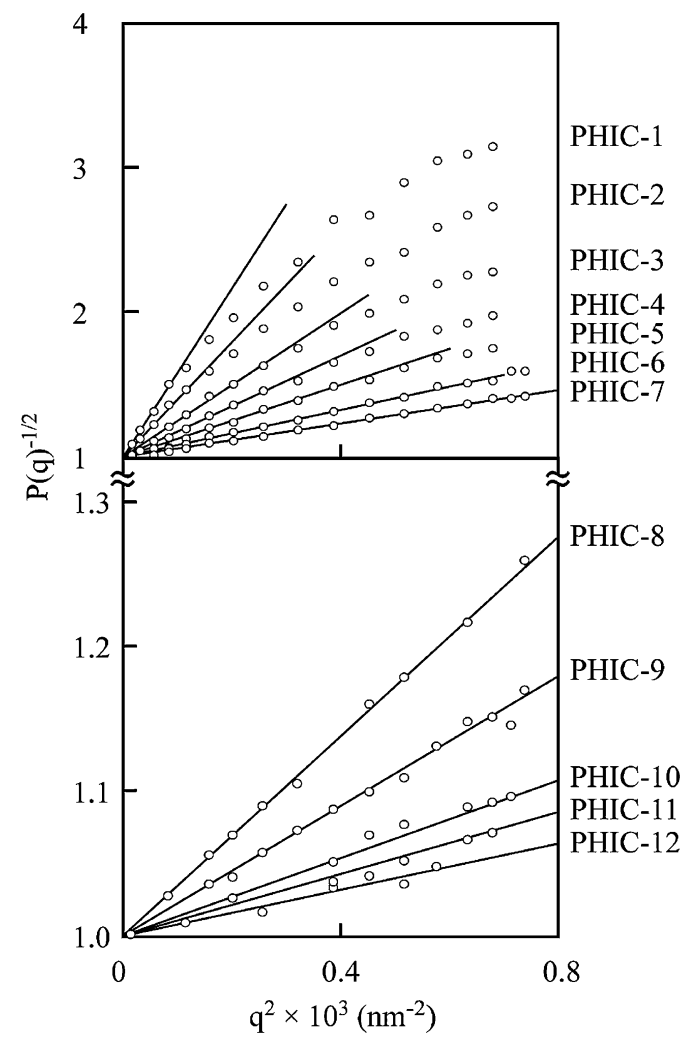

Figure 7. Angular dependence of $\mathrm{P}(q)^{-1 / 2}$ for the indicated fractions of PHIC chain fractionated by SEC-MALS in THF at $25 \pm 1{ }^{\circ} \mathrm{C}$.

Table II. Characterization results from SEC-MALS-VIS on PHIC in THF at $25 \pm 1{ }^{\circ} \mathrm{C}$

\begin{tabular}{cccccc}
\hline \multirow{2}{*}{ Sample } & $M_{\mathrm{w}} \times 10^{-5 \mathrm{a})}$ & & $\left.\left\langle\mathrm{Rg}^{2}\right\rangle_{\mathrm{z}}^{1 / 2 \mathrm{a}}\right)$ & & {$[\eta] \times 10^{-3}$} \\
\cline { 2 - 2 } \cline { 5 - 5 } \cline { 5 - 5 } & $(\mathrm{MALS})$ & & $(\mathrm{nm})$ & & $\left(\mathrm{cm}^{3} / \mathrm{g}\right)$ \\
\hline PHIC-1 & 22.5 & & 187 & - \\
PHIC-2 & 15.9 & & 154 & - \\
PHIC-3 & 10.7 & & 122 & - \\
PHIC-4 & 7.61 & & 103 & - \\
PHIC-5 & 5.78 & & 86.5 & \\
PHIC-6 & 4.03 & & 69.8 & \\
PHIC-7 & 2.97 & & 59.0 & \\
PHIC-8 & 1.98 & & 45.4 & \\
PHIC-9 & 1.43 & & 36.6 & \\
PHIC-10 & 0.964 & & 28.4 & 0.711 \\
PHIC-11 & 0.811 & & 25.3 & 0.490 \\
PHIC-12 & 0.706 & & 21.9 & 0.312 \\
\hline
\end{tabular}

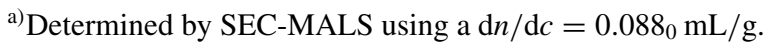
${ }^{b)}$ Determined by SEC-MALS-VIS.

According to Benoit and Doty for Kratky-Porod chain, ${ }^{39}$ the unperturbed $\left\langle\operatorname{Rg}^{2}\right\rangle_{\mathrm{KP}}$ of a mondispersed wormlike chain is expressed by

$$
\begin{aligned}
\left\langle\operatorname{Rg}^{2}\right\rangle_{\mathrm{KP}}= & \frac{L}{6 \lambda}-\frac{1}{4 \lambda^{2}}+\frac{1}{4 \lambda^{3} L} \\
& -\frac{1}{8 \lambda^{4} L^{2}}[1-\exp (-2 \lambda L)]
\end{aligned}
$$

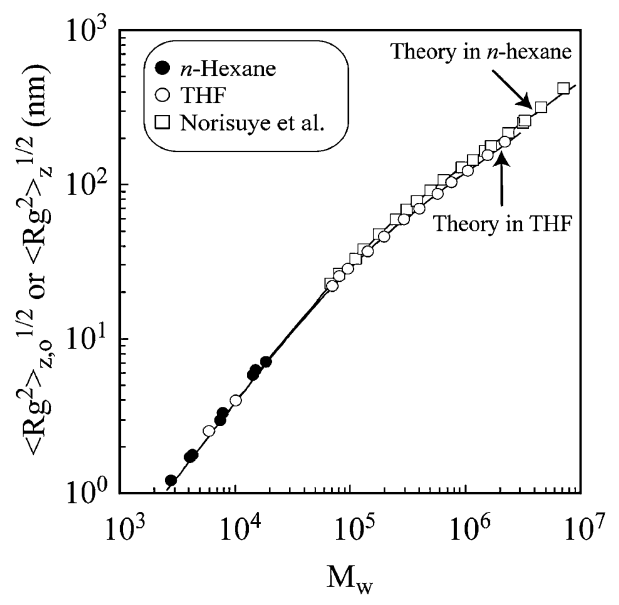

Figure 8. Molecular weight dependence of $\left\langle\operatorname{Rg}^{2}\right\rangle_{z}{ }^{1 / 2}$ and $\left\langle\operatorname{Rg}^{2}\right\rangle_{z, 0} 1 / 2$ for the macromonomers and PHIC chain in THF and $n$-hexane, together with the data reported by Norisuye et al. ${ }^{29}$ The solid lines represent the theoretical values calculated from eq 8 to 14 with the parameters in Table III.

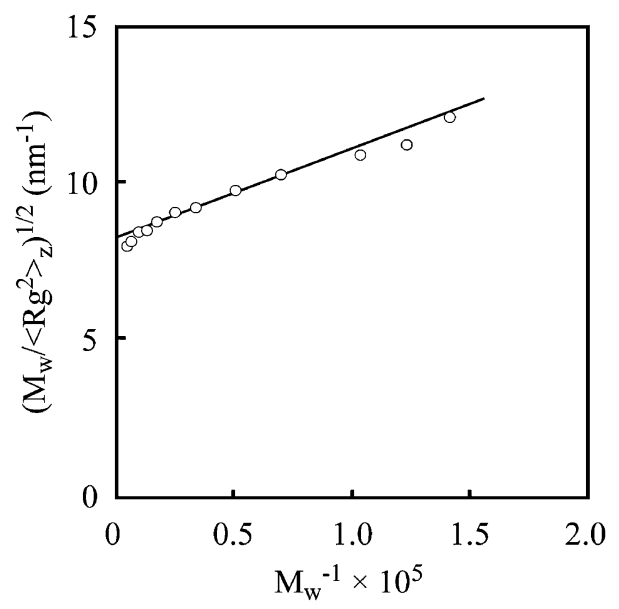

Figure 9. Plot of $\left(M_{\mathrm{w}} /\left\langle\operatorname{Rg}^{2}\right\rangle_{\mathrm{z}}\right)^{1 / 2}$ versus $M_{\mathrm{w}}{ }^{-1}$ for PHIC chains in THF at $25^{\circ} \mathrm{C}$.

Here, $\lambda^{-1}$ is the chain stiffness parameter (the Kuhn segment length) and $L$ is the contour length of the main chain related to the molecular weight $M$ by $L=M / M_{\mathrm{L}}$, with $M_{\mathrm{L}}$ being the molar mass per unit contour length. According to Norisuye et al., ${ }^{29}$ eq 9 can be approximated by

$$
\left(\frac{M}{\left\langle\operatorname{Rg}^{2}\right\rangle}\right)^{1 / 2}=\left(6 \lambda M_{\mathrm{L}}\right)^{1 / 2}\left(1+\frac{3 M_{\mathrm{L}}}{4 \lambda M}\right)
$$

with the maximum error from the exact value being $1 \%$ for $\lambda L>2$. Equation 10 indicates that $(M /$ $\left.\left\langle\operatorname{Rg}^{2}\right\rangle\right)^{1 / 2}$ plotted against $M^{-1}$ should give a straight line whose intercept and slope allow the two parameters $\lambda^{-1}$ and $M_{\mathrm{L}}$ to be evaluated.

Figure 9 shows this plot constructed from our $\left\langle\operatorname{Rg}^{2}\right\rangle_{z}$ data in THF at $25^{\circ} \mathrm{C}$. The data points follow a straight line $\left(1.43 \times 10^{5} \leq M_{\mathrm{w}} \leq 5.78 \times 10^{5}\right)$, which affords 
$63 \mathrm{~nm}$ for $\lambda^{-1}$ and $725 \mathrm{~nm}^{-1}$ for $M_{\mathrm{L}}$.

The excluded-volume effects on $\left\langle\operatorname{Rg}^{2}\right\rangle$ also have to be taken into account in the high $M_{\mathrm{w}}$ region. An example is shown in Figure 9 in which the pronounced downward deviations of the plotted points are observed. In the following, we analyzed the $\left\langle\operatorname{Rg}^{2}\right\rangle_{z}$ data with the aid of quasi-two-parameter (QTP) theory ${ }^{40-42}$ for the KP chain. In the QTP scheme, the radius expansion factor $\alpha_{\mathrm{s}}=\left(\left\langle\mathrm{Rg}^{2}\right\rangle /\left\langle\mathrm{Rg}^{2}\right\rangle_{\mathrm{KP}}\right)^{1 / 2}$ is a universal function of the scaled excluded-volume parameter $\tilde{z}$ defined by

$$
\tilde{z}=\frac{3}{4} K(\lambda L) \mathrm{z}
$$

with

$$
\mathrm{z}=\left(\frac{3}{2 \pi}\right)^{3 / 2}(\lambda B)(\lambda L)^{1 / 2}
$$

and

$$
\begin{aligned}
K(\lambda L)= & \frac{4}{3}-2.711(\lambda L)^{-1 / 2}+\frac{7}{6}(\lambda L)^{-1} \text { for } \lambda L>6 \\
K(\lambda L)= & (\lambda L)^{-1 / 2} \exp L-6.611(\lambda L)^{-1}+0.9198 \\
& +0.03516(\lambda L)\rfloor \text { for } \lambda L \leq 6
\end{aligned}
$$

Here, $\mathrm{z}$ is the conventional excluded-volume parameter and $B$ is the excluded-volume strength defined by $B=\beta / \mathrm{a}^{2}$ with $\beta$ and a being the binary cluster integral representing the interaction between a pair of beads and the bead spacing, respectively. Adopting the Domb-Barrett equation ${ }^{43}$ for $\alpha_{\mathrm{s}}{ }^{2}$, we have

$$
\begin{aligned}
\alpha_{\mathrm{s}}^{2}= & {\left[1+10 \tilde{z}+\left(\frac{70 \pi}{9}+\frac{10}{3}\right) \tilde{z}^{2}+8 \pi^{3 / 2} \tilde{z}^{3}\right]^{2 / 15} } \\
& \times\left[0.933+0.067 \exp \left(-0.85 \tilde{z}-1.39 \tilde{z}^{2}\right)\right]
\end{aligned}
$$

The comparison of the experimental data with theoretical curves calculated using eqs $8-14$ is shown in Figure 8 . The model parameters of $\lambda^{-1}, M_{\mathrm{L}}$, and $B$ for the PHIC chain in THF are summarized in Table III, together with the values reported by Norisuye et al. ${ }^{29,30}$ in $n$-hexane and Berger et al. ${ }^{32}$ in THF. Figure 8 shows that the theoretical solid curves fit the data points in THF and $n$-hexane throughout the entire range $\left(10^{3}-10^{6}\right)$ of $M_{\mathrm{w}}$. The value of $\lambda^{-1}$ in THF is somewhat smaller than that in $n$ - hexane and reported by Berger et al. in THF at $25^{\circ} \mathrm{C}$.

Intrinsic viscosities $[\eta]$ of the macromonomers determined using a capillary viscometer in THF and $n$ hexane at $25^{\circ} \mathrm{C}$ are summarized in Table I, and those determined by SEC-MALS-VIS are also in Table II. Double-logarithmic plots of [ $\eta$ ] versus $M_{\mathrm{w}}$ for PHIC chains and macromonomers in THF and $n$-hexane at $25^{\circ} \mathrm{C}$ are depicted in Figure 10, together with the data reported by Norisuye et al. ${ }^{29}$ in $n$-hexane at $25^{\circ} \mathrm{C}$. In Yamakawa-Fujii's theories, ${ }^{44-46}[\eta]$ of a wormlike cylinder is expressed as function of $\lambda^{-1}, M_{\mathrm{L}}$, and an additional hydrodynamic parameter $d_{\mathrm{B}}$, the diameter of the cylinder. A $d_{\mathrm{B}}$ value fitting our experimental curve of $\log [\eta]$ versus $\log M_{\mathrm{w}}$ to Yamakawa-Fujii's theoretical one is sought by trial and error, with $\lambda^{-1}$ and $M_{\mathrm{L}}$ fixed, respectively, to be $63 \mathrm{~nm}$ and $725 \mathrm{~nm}^{-1}$. It is found that the value of $d_{\mathrm{B}}=1.6 \mathrm{~nm}$ leads to the most satisfactory agreement with experimental data in $\mathrm{THF}$ at $25^{\circ} \mathrm{C}$. In Figure 10, the solid line corresponding to $\lambda^{-1}=63 \mathrm{~nm}, M_{\mathrm{L}}=725 \mathrm{~nm}^{-1}$, and $d_{\mathrm{B}}=$ $1.6 \mathrm{~nm}$ is seen to agree closely with the experimental values. Wormlike chain parameter determined from $[\eta]$ is also listed in Table III. Whereas the value of $\lambda^{-1}$ for PHIC chain in THF is slightly smaller than in $n$-hexane, the Kuhn segment number $(\lambda L=$

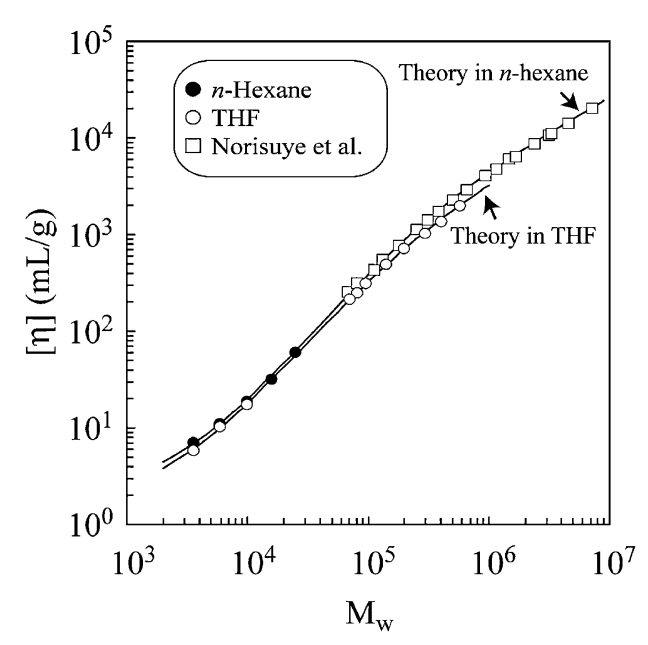

\begin{tabular}{|c|c|c|c|c|c|c|}
\hline Source & $\frac{\lambda^{-1}}{(\mathrm{~nm})}$ & $\frac{M_{\mathrm{L}}}{\left(\mathrm{nm}^{-1}\right)}$ & $\frac{\left\langle\mathrm{Rc}^{2}\right\rangle_{\mathrm{o}}^{1 / 2}}{(\mathrm{~nm})}$ & $\frac{d_{\mathrm{B}}}{(\mathrm{nm})}$ & $\begin{array}{c}B \\
(\mathrm{~nm})\end{array}$ & Solvent \\
\hline This work & 63 & 725 & $0.263^{\mathrm{a})}$ & 1.6 & 2.6 & $\mathrm{THF}$ at $25^{\circ} \mathrm{C}$ \\
\hline Berger et al. ${ }^{32}$ & 85 & $640^{\mathrm{b})}$ & - & - & - & THF at $25^{\circ} \mathrm{C}$ \\
\hline Norisuye et al. ${ }^{29,30}$ & 86 & 730 & - & 1.8 & 2.6 & $n$-hexane at $25^{\circ} \mathrm{C}$ \\
\hline
\end{tabular}

Figure 10. Molecular weight dependence of $[\eta]$ for the macromonomers and PHIC in THF and $n$-hexane, together with the data reported by Norisuye et al. ${ }^{29}$ The solid lines represent the theoretical values with the parameters in Table III.

Table III. Worm-like chain parameters determined from $\left\langle\mathrm{Rg}^{2}\right\rangle_{z}$ and $[\eta]$ for PHIC chain in THF and $n$-hexane at $25^{\circ} \mathrm{C}$

${ }^{\text {a) }}$ Determined by SAXS for VB-HIC- $n$ in $n$-hexane. ${ }^{\text {b) }}$ Assumed. 
$\lambda M_{\mathrm{w}} / M_{\mathrm{L}}$ ) of the macromonomers with $M_{\mathrm{w}}$ less than $2.45 \times 10^{4}$ in the present study is less than one, to imply that the macromonomers may be considered as a cylindrical rod.

The scattering form factor $\mathrm{P}(q)=\Delta \mathrm{I}(q) / \Delta \mathrm{I}(0)$ from the SAXS data for VB-HIC-57 in $n$-hexane at $25^{\circ} \mathrm{C}$ may be compared with the straight cylinder and the infinitely thin rod models. The scattering function for the straight cylinder with $L$ in a length and $\mathrm{d}$ in a diameter is expressed by ${ }^{47}$

$$
\begin{aligned}
\mathrm{P}(q)= & 2 \int_{0}^{\pi}\left[j_{0}\left(\frac{q L}{2} \cos \theta_{1}\right)\right]^{2} \\
& \times\left[\frac{J_{1}\left(\frac{q d}{2} \sin \theta_{1}\right)}{\frac{q d}{2} \sin \theta_{1}}\right]^{2} \sin \theta_{1} \mathrm{~d} \theta_{1}
\end{aligned}
$$

where $j_{0}(x)$ and $J_{1}(x)$ denote the 0th-order spherical Bessel function and the first-order Bessel function, respectively.

The scattering function for the infinitely thin rod is expressed by ${ }^{48}$

$$
\mathrm{P}(q)=\frac{2}{(q L)^{2}}[q L \operatorname{Si}(q L)+\cos (q L)-1]
$$

where $\operatorname{Si}(x)$ is the sine integral defined by

$$
\operatorname{Si}(x)=\int_{0}^{x} \mathrm{t}^{-1} \sin \mathrm{tdt}
$$

which approaches to $\pi / 2$ at large $x$. Comparison in Kratky plot between the experimental data of VB-HIC-57 $\left(C_{\mathrm{p}}=1.22 \times 10^{-2} \mathrm{~g} / \mathrm{mL}\right)$ in $n$-hexane at $25^{\circ} \mathrm{C}$ and the theoretical curves calculated from eqs 15 to 17 are made in Figure 11. In this figure, the thick solid and thin solid lines show the theoretical curves calculated for the straight cylinder with $M_{\mathrm{L}}=$ $730 \mathrm{~nm}^{-1}(L=10.9 \mathrm{~nm})$ and $d=0.744 \mathrm{~nm}$ and the infinitely thin rod, respectively. One sees that the scattering form factor is quantitatively described in terms of the straight cylinder model. The scattering profiles for PHIC macromonomers other than VB-HIC-57 are also good agreement with the straight cylinder model with the same model parameters of $M_{\mathrm{L}}$ and $d$. All experimental results on $\left\langle\operatorname{Rg}^{2}\right\rangle$ and $[\eta]$, together with $\mathrm{P}(q)$ allow one to conclude that the PHIC macromonomers with $n$ from 21 to 192 are considered as a stiff rod in THF and $n$-hexane.

\section{Characterization of Polymer Brushes Consisting of Rodlike Side Chains}

Figure 12 shows the cross-section Guinier plots of $\ln [q \Delta \mathrm{I}(q)]$ versus $q^{2}$ for poly(VB-HIC-46) $\left(M_{\mathrm{w}}=\right.$

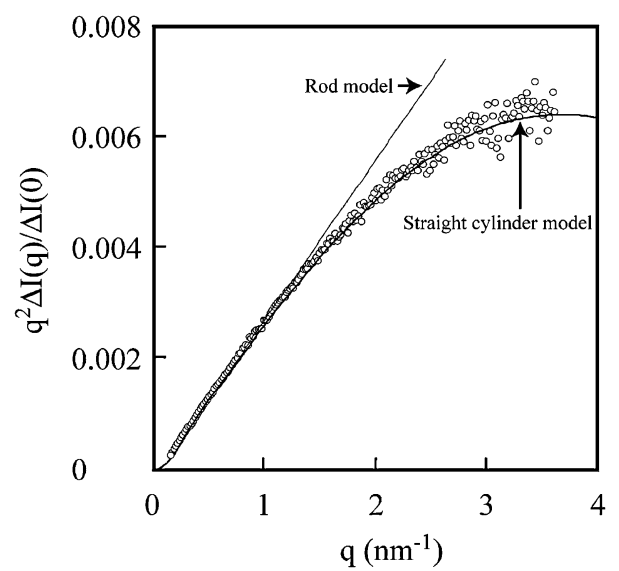

Figure 11. Kratky plot of $q^{2} \Delta \mathrm{I}(q) / \Delta \mathrm{I}(0)$ versus $q$ for VBHIC-57 $\left(C_{\mathrm{p}}=1.22 \times 10^{-2} \mathrm{~g} / \mathrm{mL}\right)$ in hexane at $25^{\circ} \mathrm{C}$. The thick solid line represents the theoretical curve for the straight cylinder with $M_{\mathrm{L}}=730 \mathrm{~nm}$ and $d=0.744 \mathrm{~nm}$ and the thin solid line represents one for the infinitely thin rod.

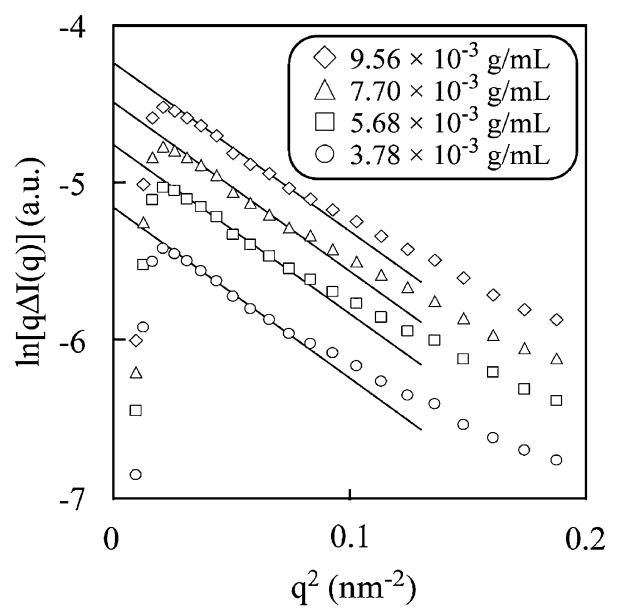

Figure 12. Cross-section plots of $\ln [q \Delta \mathrm{I}(q)]$ as a function $q^{2}$ for Poly(VB-HIC-46) in THF at $25^{\circ} \mathrm{C}$.

$\left.7.63 \times 10^{6}, M_{\mathrm{w}} / M_{\mathrm{n}}=1.36\right)$ in THF at $25^{\circ} \mathrm{C}$. The value of $\left\langle\mathrm{Rc}^{2}\right\rangle^{1 / 2}$ for poly(VB-HIC-46) was evaluated using eq 3. Figure 13 shows the dependence of $\left\langle\mathrm{Rc}^{2}\right\rangle^{1 / 2}$ on $C_{\mathrm{p}}$ and one obtains the value of $4.66 \mathrm{~nm}$ for $\left\langle\operatorname{Rc}^{2}\right\rangle_{0}{ }^{1 / 2}$ of a poly(VB-HIC-46) chain at an infinite dilution by extrapolating to $C_{\mathrm{p}}=0$. This value corresponds to the diameter of $d=13.2 \mathrm{~nm}$ for a rigid cylinder with a constant chain density throughout eq 5 . The contour length of the macromonomer, VB-HIC46 is calculated $8.34 \mathrm{~nm}$ in THF at $25^{\circ} \mathrm{C}$ by $M_{\mathrm{w}} / M_{\mathrm{L}}$. Thus, the observed value of $\mathrm{d}$ may be slightly lower than the diameter $(16.7 \mathrm{~nm})$ of the cylinder with $8.34 \mathrm{~nm}$ in a radius. When the $\left\langle\mathrm{Rc}^{2}\right\rangle_{\mathrm{o}}{ }^{1 / 2}$ determined by SAXS measurements is obtained for a straight rod consisting of two macromonomer chains $(L=$ $16.7 \mathrm{~nm}),\left\langle\operatorname{Rc}^{2}\right\rangle^{1 / 2}=(1 / 12)^{1 / 2} L=4.82 \mathrm{~nm}$, in closely agreement with the experimental $\left\langle\operatorname{Rc}^{2}\right\rangle_{0}{ }^{1 / 2}$.

In Figure 14 the plots of $\mathrm{P}(q)^{-1 / 2}$ versus $q^{2}$ for 


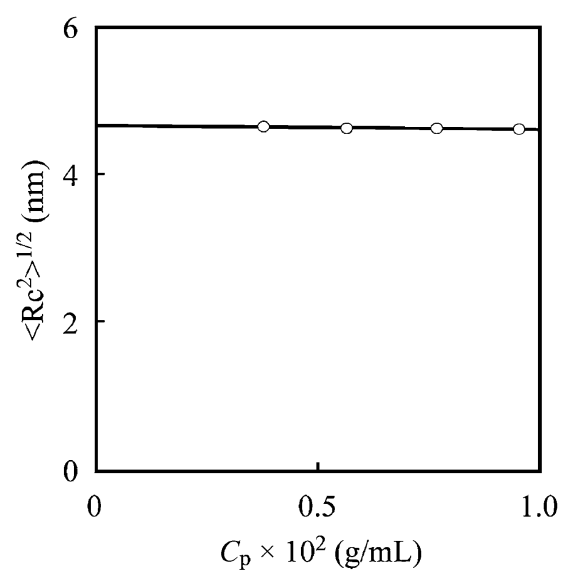

Figure 13. Plot of $\left\langle\mathrm{Rc}^{2}\right\rangle^{1 / 2}$ as a function of $C_{\mathrm{p}}$ for poly(VBHIC-46) in THF at $25^{\circ} \mathrm{C}$.

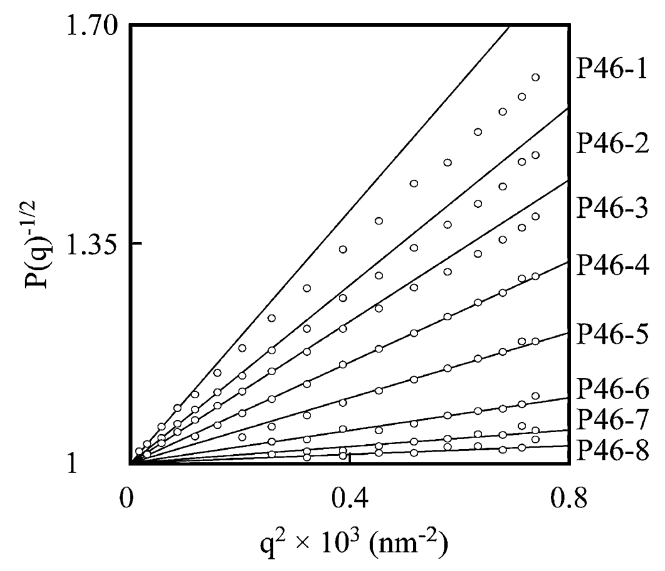

Figure 14. Angular dependence of $\mathrm{P}(q)^{-1 / 2}$ for the indicated fractions of poly(VB-HIC-46) chains fractionated by SEC-MALS in THF at $25 \pm 1^{\circ} \mathrm{C}$.

poly(VB-HIC-46) chains fractionated by SEC-MALS in THF are illustrated and one determines $\left\langle\operatorname{Rg}^{2}\right\rangle_{\mathrm{z}}{ }^{1 / 2}$ from an initial slope (denoted by solid line) by eq 7 . Molecular characteristics of the brushes are listed in Table IV. Figure 15 shows double-logarithmic plots of the $\left\langle\operatorname{Rg}^{2}\right\rangle_{Z}{ }^{1 / 2}$ versus the weight average degree of polymerization of main chain $\left(\mathrm{N}_{\mathrm{w}}\right)$ for poly(VBHIC-46) in THF, together with the data of PSt in THF at $25^{\circ} \mathrm{C}$ given by the following equation: ${ }^{49}$

$$
\left\langle\operatorname{Rg}^{2}\right\rangle^{1 / 2}=1.18 \times 10^{-2} M_{\mathrm{w}}{ }^{0.6}(\mathrm{~nm} \text {, linear) }
$$

It should be noted that the values of $\left\langle\operatorname{Rg}^{2}\right\rangle_{\mathrm{z}}{ }^{1 / 2}$ of poly(VB-HIC-46) are much larger than that of PSt with the corresponding $\mathrm{N}_{\mathrm{w}}$. This clearly implies that the main chain stiffness of poly(VB-HIC-46) is much higher than that of PSt in THF at $25^{\circ} \mathrm{C}$. In other words, the polystyrene main chain remarkably stiffens by the presence of densely located stiff rods. Another interesting point to be noted in this figure is to show an S-shaped dependence of $\left\langle\operatorname{Rg}^{2}\right\rangle^{1 / 2}{ }_{\mathrm{z}}$ on $\mathrm{N}_{\mathrm{w}}$, implying that the simple KP chain model is not applicable to
Table IV. Characterization results on poly(VB-HIC-46) by SEC-MALS in THF at $25 \pm 1{ }^{\circ} \mathrm{C}$

\begin{tabular}{cccc}
\hline \multirow{2}{*}{ Sample } & $M_{\mathrm{w}} \times 10^{-7}$ & \multirow{2}{*}{$\mathrm{N}_{\mathrm{w}}{ }^{\mathrm{b})} \times 10^{-3}$} & $\left\langle\mathrm{Rg}^{2}\right\rangle_{\mathrm{z}}^{1 / 2}$ \\
\cline { 2 - 2 } & $(\mathrm{MALS})^{\mathrm{a})}$ & & $(\mathrm{nm})$ \\
\hline P46-1 & 1.71 & 2.83 & 77.7 \\
P46-2 & 1.32 & 2.19 & 65.2 \\
P46-3 & 1.06 & 1.74 & 58.2 \\
P46-4 & 0.812 & 1.34 & 49.0 \\
P46-5 & 0.549 & 0.908 & 39.5 \\
P46-6 & 0.309 & 0.511 & 27.8 \\
P46-7 & 0.177 & 0.292 & 19.8 \\
P46-8 & 0.102 & 0.169 & 14.4 \\
\hline
\end{tabular}

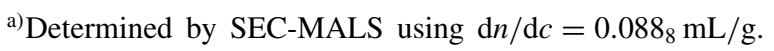
${ }^{b)}$ Weight average degree of polymerization of the main chain.

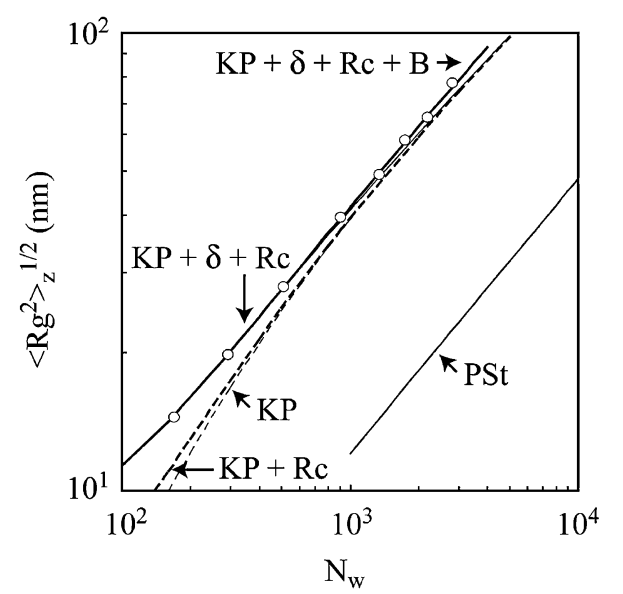

Figure 15. Plot of $\left\langle\operatorname{Rg}^{2}\right\rangle_{\mathrm{z}}{ }^{1 / 2}$ for poly(VB-HIC-46) chains versus the degree of polymerization of the main chain $\left(\mathrm{N}_{\mathrm{w}}\right)$, together with that for the linear PSt (solid line) in THF at $25^{\circ} \mathrm{C} .{ }^{49}$ The thick solid line $(\mathrm{KP}+\delta+\mathrm{Rc}+B)$ is the theoretical values for the wormlike cylinder model with the parameters indicated in Table V.

describe the dependence.

One analyzes the dependence of $\left\langle\operatorname{Rg}^{2}\right\rangle_{\mathrm{z}}{ }^{1 / 2}$ on $\mathrm{N}_{\mathrm{w}}$ for poly(VB-HIC-46), based on the cylindrical wormlike chain model with an end effect. Whereas the eq 10 was applied to the present data to determine $\lambda^{-1}$ and $M_{\mathrm{L}}$, unreasonable value of $M_{\mathrm{L}}$ was obtained. This is most likely due to the end effect. Terao and Nakamura et al. ${ }^{50}$ reported that in the polymacromonomer consisting of flexible PSt chains, some side chains near the main chain ends contribute toward apparently increasing the total contour length of the main chain. This end effect may be remarkable in the case of the brushes with the rodlike side chains. This situation is schematically shown in Figure 16, in which $\delta / 2$ stands for the contribution of side chains to the main chain contour at each end. Since the determination of four parameters of $\lambda^{-1}, M_{\mathrm{L}}, \delta$, and $B$ are considerably difficult, one assumes $M_{\mathrm{L}}=M_{\mathrm{o}} / 0.252$ $\mathrm{nm}=2.40 \times 10^{4} \mathrm{~nm}^{-1}$, where $M_{\mathrm{o}}$ is $M_{\mathrm{w}}$ of VB- 


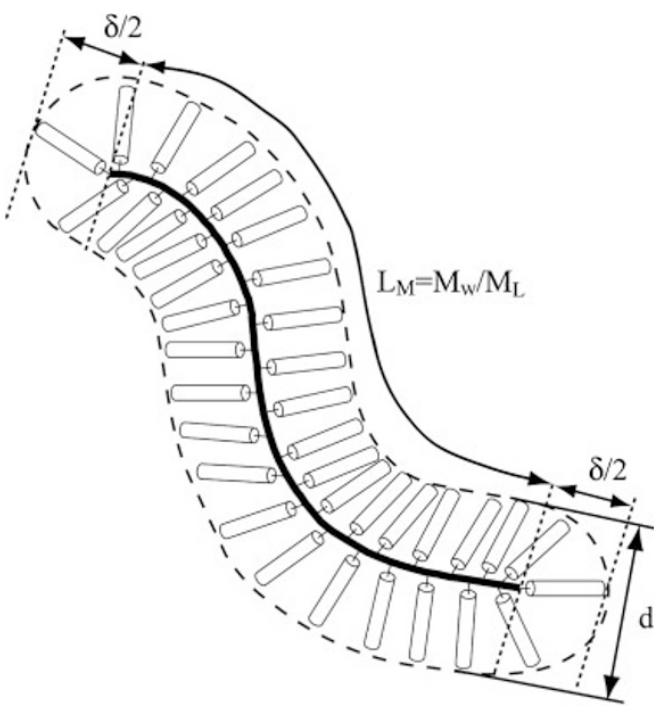

Figure 16. Schematic picture of the end effect of the side chains on the contour length of the polymacromonomer molecule.

HIC-46, $6.05 \times 10^{3}$ as shown in Table I. The value of $\delta$ corresponds to the twice contour length of the VBHIC-46 and is given by

$$
\delta=\frac{2 M_{\mathrm{o}}}{M_{\mathrm{L}}(\mathrm{PHIC} \text { in THF })}
$$

where $M_{\mathrm{L}}(\mathrm{PHIC}$ in $\mathrm{THF})=725 \mathrm{~nm}^{-1}$, as shown in Table III. The total contour length $L$ with the end effect for the brushes is then expressed by

$$
L=L_{\mathrm{M}}+\delta
$$

where $L_{\mathrm{M}}\left(=M_{\mathrm{w}} / M_{\mathrm{L}}\right)$ is the contour length of the main chain. An $\lambda^{-1}$ value fitting our experimental data of $\log \left\langle\operatorname{Rg}^{2}\right\rangle_{\mathrm{z}}$ versus $\log M_{\mathrm{w}}$ to theoretical curve using eqs $8,9,19$, and 20 is sought by trial and error, with $M_{\mathrm{L}},\left\langle\operatorname{Rc}^{2}\right\rangle_{\mathrm{o}}{ }^{1 / 2}$, and $\delta$ fixed, respectively, to be $2.40 \times 10^{4} \mathrm{~nm}^{-1}, 4.66 \mathrm{~nm}$, and $16.7 \mathrm{~nm}$. It is found that the value of $\lambda^{-1}=48 \mathrm{~nm}$ leads to the most satisfactory agreement (denoted by $\mathrm{KP}+\delta+\mathrm{Rc}$ ) with the first three experimental points in the low molecular weight (the Kuhn segment number $(\lambda L)$ is less than $3)$. The final parameter, $B$ is determined by fitting the experimental data in the high $\mathrm{N}_{\mathrm{w}}$. The parameters determined are summarized in Table V. In Figure 15, the solid line (denoted by $\mathrm{KP}+\delta+\mathrm{Rc}+B$ ) corresponding to $\lambda^{-1}=48 \mathrm{~nm}, M_{\mathrm{L}}=2.40 \times 10^{4} \mathrm{~nm}^{-1}$, $\left\langle\operatorname{Rc}^{2}\right\rangle_{\mathrm{o}}{ }^{1 / 2}=4.66 \mathrm{~nm}, \delta=16.7 \mathrm{~nm}$ and $B=6.0 \mathrm{~nm}$ is seen to agree closely with the experimental data. The relationship between the main chain stiffness and the side chain length is under study and will be published soon.

Figure 17 shows SFM images for poly(VB-HIC-46) $\left(M_{\mathrm{w}}=7.63 \times 10^{6}, M_{\mathrm{w}} / M_{\mathrm{n}}=1.36\right)$ on a mica surface at room temperature. Single, high molecular weight, cylindrical brush-like macromolecule with
Table V. Worm-like chain parameters

\begin{tabular}{|c|c|c|c|c|}
\hline$\lambda^{-1}$ & $M_{\mathrm{L}} \times 10^{-4 \mathrm{a})}$ & $\left\langle\mathrm{Rc}^{2}\right\rangle_{\mathrm{o}}^{1 / 2 \mathrm{~b})}$ & $\delta^{\mathrm{c})}$ & B \\
\hline$(\mathrm{nm})$ & $\left(\mathrm{nm}^{-1}\right)$ & $(\mathrm{nm})$ & $(\mathrm{nm})$ & $(\mathrm{nm})$ \\
\hline 48 & 2.40 & 4.66 & 16.7 & 6.0 \\
\hline
\end{tabular}
for poly(VB-HIC-46) in THF at $25^{\circ} \mathrm{C}$ mol. ${ }^{\text {b) }}$ Determined by SAXS. ${ }^{\text {c) }}$ Calculated from $\delta=2 M_{\mathrm{o}} /$ $M_{\mathrm{L}}\left(\mathrm{PHIC}\right.$ in THF), $M_{\mathrm{L}}(\mathrm{PHIC}$ in THF $)=725 \mathrm{~nm}^{-1}$ in THF at $25^{\circ} \mathrm{C}, M_{\mathrm{o}}=6050 \mathrm{~g} / \mathrm{mol}$.

ca. $15 \pm 1 \mathrm{~nm}$ in thickness on a mica surface is clearly observed. The thickness in the cross-sectional direction may be comparable to two macromonomer $\operatorname{rods}(2 L=16.7 \mathrm{~nm})$ determined by SAXS measurements in THF.

\section{CONCLUSIONS}

SEC-MALS, small-angle X-ray scattering (SAXS), and viscosity measurements were made on tetrahydrofuran (THF) and $n$-hexane of PHIC macromonomers and higher molecular weight PHIC chains than the macromonomers. The molecular weight dependence of $\left\langle\operatorname{Rg}^{2}\right\rangle_{z}$ and intrinsic viscosity $[\eta]$ of the macromonomers and PHIC chains in THF at $25^{\circ} \mathrm{C}$ were quantitatively described by the wormlike chain model with the parameters, $\lambda^{-1}=63 \mathrm{~nm}, M_{\mathrm{L}}=725 \mathrm{~nm}^{-1}$, and $d_{\mathrm{B}}=1.6 \mathrm{~nm}$. The SAXS scattering profile of the macromonomers in $n$-hexane at $25^{\circ} \mathrm{C}$ was also perfectly described in terms of the straight cylinder model. All experimental results on $\left\langle\mathrm{Rg}^{2}\right\rangle$ and $[\eta]$, together with $\mathrm{P}(q)$ for PHIC macromonomers show that the PHIC macromonomers with $n$ from 21 to 192 are considered as a stiff rod in THF and $n$-hexane. Cylindrical brushes consisting of polystyrene as a main chain and PHIC chains as a side chain were prepared by homopolymerizations of VB-HIC-46 and their dimensional properties were also investigated in THF at $25^{\circ} \mathrm{C}$ by SAXS and SEC-MALS measurements. The molecular weight dependence of $\left\langle\operatorname{Rg}^{2}\right\rangle_{z}$ of the brushes was quantitatively explained by the wormlike cylinder model with the parameters of $\lambda^{-1}=48 \mathrm{~nm}, M_{\mathrm{L}}=2.40 \times$ $10^{4} \mathrm{~nm}^{-1},\left\langle\operatorname{Rc}^{2}\right\rangle_{\mathrm{o}}{ }^{1 / 2}=4.66 \mathrm{~nm}$, and $\delta=16.7 \mathrm{~nm}$. The main chain stiffness of the brush remarkably increases by the presence of densely located rodlike side chains.

Acknowledgment. We sincerely appreciated to Professor, Takahiro Sato, Osaka University for many valuable comments on the characterization of PHIC chain in THF. Support in part by Grants-in-Aid from the Ministry of Education, Science, Sports and Culture of Japan (16550105) and by The Foundation for Japanese Chemical Research are gratefully acknowledged. 

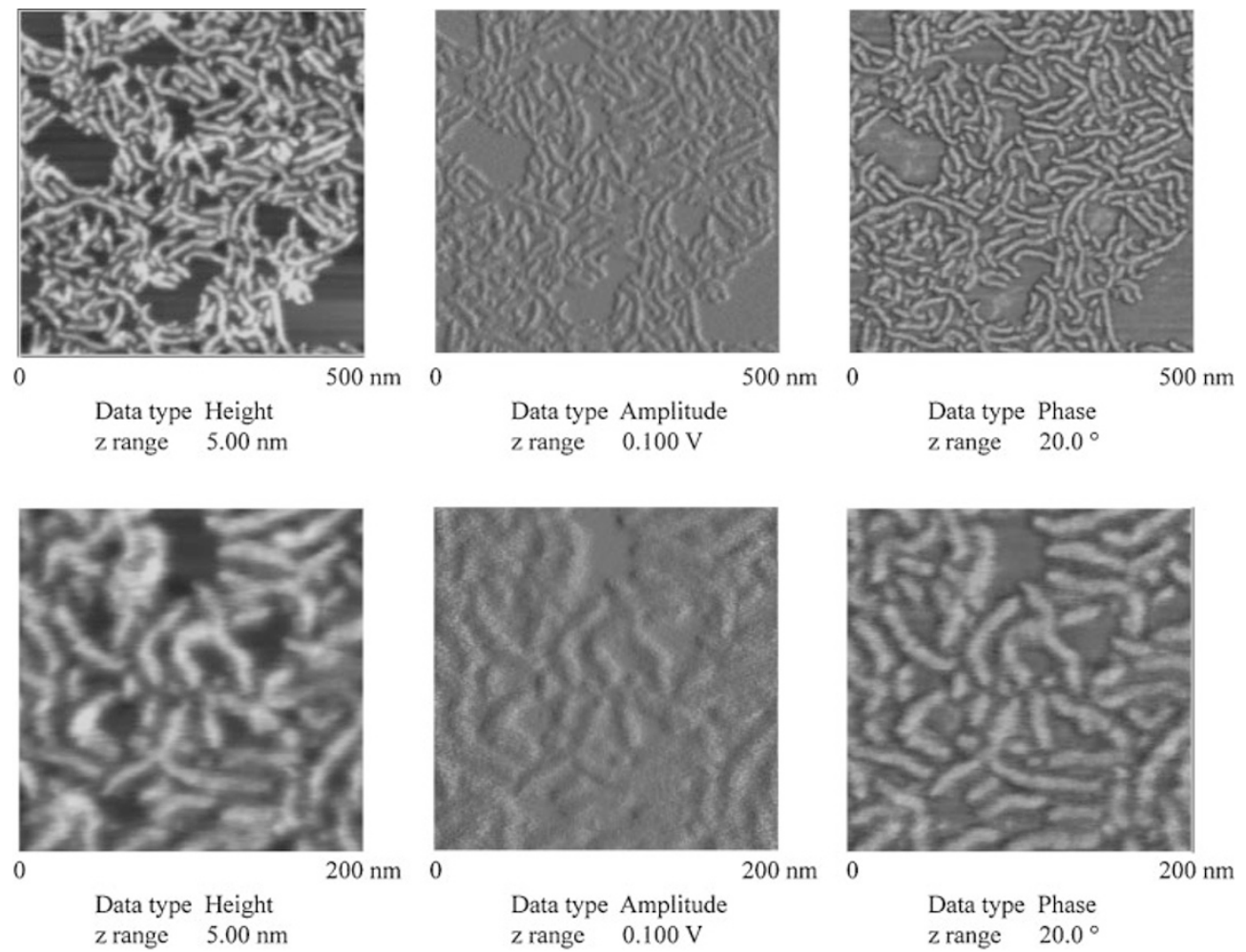

Figure 17. SFM images for poly(VB-HIC-46) $\left(M_{\mathrm{w}}=7.63 \times 10^{6}, M_{\mathrm{w}} / M_{\mathrm{n}}=1.36\right)$ on a mica at room temperature.

\section{REFERENCES}

1. K. Ito, Prog. Polym. Sci., 23, 581 (1998).

2. K. Ito and S. Kawaguchi, Adv. Polym. Sci., 142, 129 (1999).

3. S. Kawaguchi and K. Ito, Adv. Polym. Sci., 175, 299 (2005).

4. N. Hadjichristidis, M. Pitsikalis, H. Iatrou, and S. Pispas, Macromol. Rapid Commun., 24, 979 (2003).

5. M. Wintermantel, M. Schmidt, Y. Tsukahara, K. Kajiwara, and S. Kohjiya, Macromol. Rapid Commun., 15, 279 (1994).

6. Y. Tsukahara, K. Tsutsumi, Y. Yamashita, and S. Shimada, Macromolecules, 23, 5201 (1990).

7. S. Desvergne, V. Héroguez, Y. Gnanou, and R. Borsali, Macromolecules, 38, 2400 (2005).

8. K. Terao, Y. Takeo, M. Tazaki, Y. Nakamura, and T. Norisuye, Polym. J., 31, 193 (1999).

9. K. Terao, Y. Nakamura, and T. Norisuye, Macromolecules, 32, 711 (1999).

10. K. Terao, T. Hokajo, Y. Nakamura, and T. Norisuye, Macromolecules, 32, 3690 (1999).

11. K. Terao, S. Hayashi, Y. Nakamura, and T. Norisuye, Polym. Bull., 44, 309 (2000).

12. T. Hokajo, K. Terao, Y. Nakamura, and T. Norisuye, Polym. J., 33, 481 (2001).

13. Y. Nakamura and T. Norisuye, Polym. J., 33, 874 (2001).

14. W. Radke, S. Roos, H. M. Stein, and A. H. E. Müller, Macromol. Symp., 101, 19 (1996).

15. K. Ito, Y. Tomi, and S. Kawaguchi, Macromolecules, 25, 1534 (1992).

16. S. Kawaguchi, K. Akaike, Z.-M. Zhang, H. Matsumoto, and K. Ito, Polym. J., 30, 1004 (1998).

17. S. Kawaguchi, M. Maniruzzaman, K. Katsuragi, H.
Matsumoto, Iriany, K. Ito, N. Hugenberg, and M. Schmidt, Polym. J., 34, 253 (2002).

18. N. Gunari, M. Schmidt, and A. Janshoff, Macromolecules, 39, 2219 (2006).

19. Y. Cai, M. Hartenstein, and A. H. E. Müller, Macromolecules, 37, 7484 (2004).

20. R. Djalali, N. Hugenberg, K. Fischer, and M. Schmidt, Macromol. Rapid Commun., 20, 444 (1999).

21. H.-i. Lee, W. Jakubowski, K. Matyjaszewski, S. Yu, and S. S. Sheiko, Macromolecules, 39, 4983 (2006).

22. S. S. Sheiko, M. Gerle, K. Fischer, M. Schmidt, and M. Möller, Langmuir, 13, 5368 (1997).

23. M. O. Gallyamov, B. Tartsch, A. R. Khokhlov, S. S. Sheiko, H. G. Börner, K. Matyjaszewski and M. Möller, J. Microscopy, 215, 245 (2004) and references cited in.

24. M. Saariaho, A. Subbotin, I. Szleifer, O. Ikkala, and G. ten Brinke, Macromolecules, 32, 4439 (1999).

25. A. Subbotin, M. Saariaho, R. Stepanyan, O. Ikkala, and G. ten Brinke, Macromolecules, 33, 6168 (2000).

26. B. Zhang, K. Fischer, and M. Schmidt, Macromol. Chem. Phys., 206, 157 (2005).

27. M. Kikuchi, S. Kawaguchi, and K. Nagai, Des. Monomers Polym., 7, 603 (2004).

28. S. Kawaguchi, T. Mihara, M. Kikuchi, L. T. N. Lien, and K. Nagai, Macromolecules, in press.

29. H. Murakami, T. Norisuye, and H. Fujita, Macromolecules, 13, 345 (1980).

30. T. Norisuye, A. Tsuboi, and A. Teramoto, Polym. J., 28, 357 (1996).

31. T. E. Patten and B. M. Novak, J. Am. Chem. Soc., 118, 1906 (1996).

32. M. N. Berger and B. M. Tidswell, J. Polym. Sci. Symp., 42, 
1063 (1973).

33. T. Ueki, Y. Hiragi, M. Kataoka, Y. Inoko, Y. Amemiya, Y. Izumi, H. Tagawa, and Y. Muroga, Biophys. Chem., 23, 115 (1985).

34. M. L. Huggins, J. Am. Chem. Soc., 64, 2716 (1942).

35. D. F. Mead and R. M. Fuoss, J. Am. Chem. Soc., 64, 277 (1942).

36. F. W. Billmeyer, Jr., J. Polym. Sci., 4, 83 (1949).

37. O. Glatter and O. Kratky, "Small Angle X-ray Scattering," Academic Press, London, 1982.

38. T. Konishi, T. Yoshizaki, T. Saito, Y. Einaga, and H. Yamakawa, Macromolecules, 23, 290 (1990).

39. H. Benoit and P. Doty, J. Phys. Chem., 57, 958 (1953).

40. H. Yamakawa and W. H. Stockmayer, J. Chem. Phys., 57, 2843 (1972).

41. H. Yamakawa and J. Shimada, J. Chem. Phys., 83, 2607
(1985).

42. J. Shimada and H. Yamakawa, J. Chem. Phys., 85, 591 (1986).

43. C. Domb and A. J. Barrett, Polymer, 17, 179 (1976).

44. H. Yamakawa and M. Fujii, Macromolecules, 7, 128 (1974).

45. H. Yamakawa and T. Yoshizaki, Macromolecules, 13, 633 (1980).

46. T. Yoshizaki, I. Nitta, and H. Yamakawa, Macromolecules, 21, 165 (1988).

47. N. Saito and Y. Ikeda, J. Phys. Soc. Jpn., 6, 305 (1951).

48. T. Neugebauer, Ann. Physik, 42, 509 (1943).

49. Y. Nakamura, Y. Wan, J. W. Mays, H. Iatrou, and N. Hadjichristidis, Macromolecules, 33, 8323 (2000).

50. K. Amitani, K. Terao, Y. Nakamura, and T. Norisuye, Polym. J., 37, 324 (2005). 